\title{
Bipolarity and War: The Role of Capability Concentration and Alliance Patterns among Major Powers, 1816-1965
}

\author{
FRANK WHELON WAYMAN \\ University of Michigan-Dearborn
}

\begin{abstract}
This paper examines the relationship of war to power concentration and alliance configuration among the major powers. It does so by developing a theoretical argument from the literature on bipolarity and multipolarity. The paper suggests that bipolarity has two components - power distribution and alliance clustering. The two, it is argued, have 'opposite' effects on warfare in the major power system: power bipolarity minimizes the magnitude of those wars that do break out, while alliance bipolarity increases the likelihood that a war will occur. Correlational evidence, drawn from the Correlates of War data set, is supportive of both hypotheses for the twentieth century. The power polarity hypothesis is also confirmed for the nineteenth century, but the alliance polarity hypothesis seems disconfirmed for that century, perhaps because of the effects of hostility on the balance of power alliance structures of that era. The conceptual framework and findings of the present paper allow one the reexamine the classic debate on the relative probabilities of war in bipolar and multipolar systems. The insights of Deutsch and Singer on the one hand and Waltz on the other appear to be more consistent with each other than heretofore recognized. Key elements of both the Waltz and the Deutsch and Singer arguments are supported by the findings. On the other hand, more recent, empirical studies by Bueno de Mesquita and others are critiqued on the basis of the present paper's theoretical perspective and empirical findings.
\end{abstract}

\section{Polarization and war}

One of the great debates in the study of international conflict involves the relation between the polarization of an international system and the outbreak of war. ${ }^{1}$ In its classic and simplest form, as articulated by Waltz $(1964,1967)$ and by Deutsch \& Singer (1964), this debate centers on whether 'bipolarity' or 'multipolarity' is more likely to lead to war. The present paper proposes to integrate partially the two sides in this debate through a new analytic framework. This new framework is necessary for three reasons. First, the distinction between bipolarity and multipolarity, like the distinction between liberal and conservative, is multidimensional in character; just as there are different dimensions of liberalism, so there are different dimensions of bipolarity. While this point has been made by a number of scholars, including Rapkin et al. (1979) and Snyder \& Diesing (1977), the implications for the classic literature and for empirical research on war and peace have not been adequately examined; the present paper will investigate both such implications. Second, while it is not fully realized by scholars, sometimes the major power system is neither bipolar nor multipolar, but rather purely multipolar on one dimension and purely bipolar on another; the miniscule inter-dimension correlations documented below should help drive this point home and raise serious questions about much of the empirical work that has been done to test the Waltz and Deutsch-Singer hypotheses. Third, the theoretical and empirical work in the present paper increases the support for the contention that (a), contrary to the conventional wisdom, a multipolar power distribution breeds large scale wars, while (b) multipolarity on other dimensions - the 'spatial' or 'horizontal' dimensions of friendship and hostility patterns - may lead to peace. In the paper, correlation and regression analysis of data from the Correlates of War Project is used to explore this relationship of polarization to warfare over the period from 1815 to 1965 . The data analysis, 
while ambiguous at points, suggests that spatial, or alignment, bipolarity increases the threat of war, while power bipolarity decreases that threat.

\section{The debate on polarity}

'Bipolarity' usually refers to a situation in which the international system or one of its subsystems is dominated by two superpowers, each with a supporting bloc of relatively weak allies. 'Multipolarity' usually refers to an opposite condition in which more than two great powers play dominant roles in the international system. Deutsch and Singer argue that for two reasons multipolarity is more stable - i.e., more likely to remain in a steady, peaceful state - than bipolarity. First, in a bipolar world, all conflicts involve the nations of one side against those of the other, so that each side comes to regard the other as the enemy. In a multipolar world, interaction patterns increase in complexity and variety. An enemy on one issue becomes an ally on another. Cross-cutting cleavages and cross-pressures decrease the likelihood that implacable hostilities will develop (Deutsch \& Singer, op.cit., p. 394). Second, as the number of poles increases, each actor is forced to divide his attention among more and more poles. This divided attention makes escalating arms races of the type Richardson describes less likely (ibid., p. 399).

Waltz counters with the thesis that bipolarity is more stable than multipolarity. Selecting the Cold War between the United States and the Soviet Union as a bipolar system, he argues that the second-strike capabilities and militarily dominant position of the two superpowers (1) deterred any possible attack the one might launch on the other, and (2) allowed each to control extremists in their own camps (as, for example, the U.S. did against Britain and France when they seized the Suez Canal in 1956). The result of these two restraints was a relatively peaceful Cold War era despite high tensions. Waltz also addresses the matter of divided attention, but argues that as the number of poles increase, divided attention breeds miscalculation and thereby increases the probability of war.
Deutsch, Singer and Waltz carried on their debate about polarity in the aftermath of Kaplan's System and Process in International Politics (1957), which popularized the discussion of power systems in terms of the ideal types of multipolarity (the classic balance of power) and loose or tight bipolarity. It is a thesis of this paper that the balance of power and alliance polarization should not be treated in terms of such ideal types, but should rather be treated in terms of the variables used to compute the product-moment about the center of a space (Wallace 1973). In such an analysis, the two key variables are the weight, or power of a country, and the degree of hostility or friendship which obtains in its relations with other nation-states in the system.

\section{Measuring weights and hostility}

In applying this model to the real world, the weight of each state and the degree of its hostility or friendship to other states must be measured. Measuring the weight, or power, of a country has been approached in several ways. One method has been to look for concrete power-attributes, or capabilities, which can be used as measures of countries' power (Sabrosky 1975, Knorr 1955). This approach has been criticized on grounds that (1) 'power' should be reserved for the ability of country A to modify the behavior of country B; (2) attributes, such as GNP and military spending, only provide certain tools or capabilities that can be converted into power, and do not represent power itself; (3) power, unlike these attributes, is variable across a limited domain and scope (Dahl 1970, p. 18); (4) the capabilities or power of a set of countries may not be additive when they form an alliance; (5) power is an extremely ambiguous, and perhaps superfluous, concept in social science analysis (Riker 1962, 1969).

A second approach to the measurement of power is to look for measures of perceived national power. This approach assumes that 'power', in the phrase 'the balance of power', means the perceived power of a country in the minds of statesmen and other attentive observers of the international system. Per- 
ceived power is thus a key factor in the minds of statesmen as they adjust their national policies and alliance patterns. This formulation assumes that statesmen and others make judgments about the power of states on a ratio scale. These judgments are conceivably recoverable through some instrument such as a questionnaire.

A third approach in the literature on national power is to look for objective attributes that predict perceived power. Alcock \& Newcombe (1970), studying the perceptions of students and citizens in Canada and Latin America, concluded that GNP and military expenditures are both excellent predictors of perceived national power, with military expenditures being a better predictor if warring nations are included in the ratings. Their approach integrates the first two by demonstrating that attributes, such as GNP, are highly correlated with perceived power.

The second key variable, the degree of hostility between pairs of nations, can be measured by questionnaire administration (Klingberg 1941), analysis of alliance data (Wallace, op.cit.), analysis of voting in or membership in international organizations, analysis of trade data (Goldman 1974, p. 134ff., Wall 1972), or content analysis. Such data can then be scaled through the use of multidimensional scaling routines. Efforts based on perceptual data (Klingberg, op.cit.) and on aggregate data (Wallace, op.cit.) have been productive in this way. For ease of presentation, these analyses can often be presented visually in graphs in which friendly nations cluster close together and hostile nations are distant from one another. The present paper analyzes pairs of nations in terms of the degree of hostile or friendly relations between their governments. Sometimes hostile pairs are labelled 'distant' from each other, and the reader should realize that this is a spatial metaphor for hostility between the governments, not a description of geographic distance.

\section{Propositions about polarization}

A model involving weight and locations suggests the following definitions and propositions about polarity.

Definition 1. A system is power bipolar when capabilities are so distributed that two dominant hostile powers are more powerful than other actors to a degree that gives the dominant powers autonomy in self-defense.

The second-strike capabilities of the U.S. and the Soviet Union in the 1960s would illustrate this concept.

Definition 2. A system is power multipolar when capabilities are more evenly distributed than in the power bipolar condition, and when hostility is still high.

Definition 3. A system is cluster bipolar when most or all of the states in the system are tightly packed into two political clusters, with high mutual hostility, and very few or no states play intermediate or cross-cutting roles. In the perfect form of tight cluster bipolarity, the members are all mutually closer to each other than any of them are to any member of the other cluster.

Definition 4. A system is cluster multipolar when the states are more evenly distributed throughout the space, with many opportunities for intermediaries and many crosscutting loyalties to moderate hostility.

Power bipolarity and power multipolarity are mutually exclusive categories. So are cluster bipolarity and cluster multipolarity. It is essential to realize, however, that a system that is power bipolar can be either cluster bipolar or cluster multipolar, and that a power multipolar system can likewise be either cluster multipolar or cluster bipolar. ${ }^{2}$ Thus, in Table I, starting clockwise from the upper left corner, the reader can examine how Europe has proceeded through four successive types of international system since 1919. In the period after World War I 
Table 1. Two Dimensions of Polarization.

\begin{tabular}{|c|c|c|c|}
\hline & & Coalition config & \\
\hline & $\begin{array}{l}\text { Power } \\
\text { multi- }\end{array}$ & $\begin{array}{l}\text { Cluster } \\
\text { multipolarity } \\
\text { (Many clusters) }\end{array}$ & $\begin{array}{l}\text { Cluster } \\
\text { bipolarity } \\
\text { (Two clusters) }\end{array}$ \\
\hline $\begin{array}{l}\text { Power } \\
\text { conces.- }\end{array}$ & $\begin{array}{l}\text { polarity } \\
\text { (Dispersed } \\
\text { capabilities) }\end{array}$ & $\begin{array}{l}\text { European } \\
\text { System } \\
1919-1939 \\
\end{array}$ & $\begin{array}{l}\text { European } \\
\text { System } \\
1941-1945\end{array}$ \\
\hline tration & $\begin{array}{l}\text { Power } \\
\text { bipolarity } \\
\text { (Concentrated }\end{array}$ & $\begin{array}{l}\text { Aspects of the } \\
\text { European } \\
\text { System } \\
1965-1975\end{array}$ & $\begin{array}{l}\text { European } \\
\text { System } \\
1948-1955\end{array}$ \\
\hline
\end{tabular}

and before the rise of Hitler, the European state system, in which the United States was by now an actor, was power multipolar and cluster multipolar.

In World War II, the European system was cluster bipolar - with virtually all the key actors locked in a deadly conflict between fascist and anti-fascist coalitions - but power multipolar - with Britain, the United States, and the Soviet Union depending on each other for support against the Axis onslaught. In the Cold War of the early 1950s, Europe was power bipolar and cluster bipolar. By the early 1970s, Europe remained power bipolar, but had moved towards cluster multipolarity, to some extent with the partial dissolution of the tightly clustered Cold War alliance patterns, but much more as indicated by shifting trade and economic indicators of polarization. ${ }^{3}$

A fifth definition is useful for the development of the argument:

Definition 5. A system is unipolar if none of the states in the system are hostile enough to each other to induce mutual fear and aggressive designs.

Rapkin, Thompson, and Christopherson have drawn similar distinctions. Differences in terminology should not obscure these similarities. What they call 'bipolarity' is here called 'power bipolarity'. What they call 'bipolarization' is here called 'cluster bipolarity'. The terminology used here is simply useful for drawing out the implications of the Deutsch-Singer-Waltz debate. While Rapkin, Thompson, and Christopherson have expressed the key distinction and traced its origins in empirical studies by a host of authors, they did not trace its implications back to the Deutsch-Singer-Waltz debate or use insights gleaned from such a literature review to test the Deutsch-Singer-Waltz hypotheses about system structure and war; this effort will be undertaken in the present paper. Hence, the following set of propositions provides the theoretical rationale for emphasizing the distinction between power and spatial polarity.

Proposition 1. The greater the number of pairs of states in the system with a degree of hostility above some critical level, the greater the likelihood of war.

This proposition states an obvious, but nonetheless important, relationship: hostility leads to mutual fear and a high probability of warfare. Two countries close together 
(again, close in the cluster analysis of friendship, not necessarily in geographic proximity) have by definition compatible interests, and tend to identify with each other to the point where war between them is unthinkable. Examples in the contemporary world would be Denmark and Sweden, or Canada and the United States (Deutsch et al., op.cit.). It is when actors are extremely distant from each other along some dimension - as in the case of Israel and the P.L.O. - that the potential for violence is high.

Proposition one correctly asserts that hostility increases the likelihood of war. To fully understand proposition one, we must place it in the context of two other propositions. How the system is polarized affects the likelihood of the war becoming massive (examined in proposition two) and even the strength of the relationship between hostility and war (examined in proposition three).

Proposition 2. In a system that is power bipolar, warfare if it occurs is likely to be minimal and not system-engulfing, whereas in a system that is power multipolar, warfare will be of higher magnitude if it occurs.

When the strongest powers in the system are fairly independent of support from their allies, as they are under power bipolarity, they can confidently manage a crisis in which one of their allies has taken a position of extreme hostility towards the enemy coalition. Since such a self-sufficient big power does not really need the ally in a vital sense, the ally can be left isolated until it sees the dangers of its extreme position and compromises that position. When the big powers are not self-sufficient, any member of their coalition which takes an extreme position on an issue has a chance of dragging the big power, and thence the whole alliance, into a conflagration. The classic instance of such power multipolar behavior is World War I. In 1914, the Central Powers (Germany and Austria-Hungary) were in an inferior position in terms of capabilities (Sabrosky, op.cit.).
Germany felt isolated and surrounded by enemies on two fronts. When Germany's sole European ally, Austria-Hungary, became involved in a dispute with Serbia over the assassination of Austrian Archduke Ferdinand, Germany gave Austria-Hungary a 'blank check'. Confident of German backing, Austria-Hungary delivered a set of unreasonable demands to Serbia, refused to accept the Serbian note capitulating to the demands, and prepared to invade Serbia. This induced Russian mobilization, which precipitated German activation of the Schlieffen plan, which in turn plunged most of Europe into a massive war.

A second example of power multipolarity is the outbreak of the Great Peloponnesian War (432-404 B.C.) between Athens and Sparta. In the Greek system, both Athens and Sparta felt threatened by each other, and relied on elaborate coalitions for security. Corcyra, a friend of Athens, became involved in a dispute with Corinth, an ally of Sparta. Keeping the Corcyrean navy from falling into Corinthian hands was as critical to Athenian military defense as Corinth's wealth was to any Spartan war effort. Athens could not tolerate a Corcyrean defeat, nor could Sparta tolerate a Corinthian defeat. Despite the attempts of statesmen in Sparta and Athens to arbitrate the dispute, Athens was forced to defend Corcyra, and Corinth was able to convince Sparta and her allies to go to war against Athens (Kagan 1969).

Power bipolarity has characterized the era of thermonuclear confrontation between the United States and the Soviet Union. As Waltz noted in the articles cited above, these power relationships have forced the superpowers to treat each other with great care, to manage conflicts so as to prevent their escalation, and have allowed the superpowers to restrain the behavior of their allies. Of course, the danger of severe warfare remains if a conflict starts between the superpowers and escalates into a nuclear war. But so far the empirical results have been an era in which Soviet and American troops have avoided combat with each other and no system-wide wars have broken out. 
Proposition 3. In a system that is cluster bipolar, the amount of warfare per year is likely to be large, whereas in a cluster multipolar system, warfare is likely to be of lower magnitude per unit of time.

This third proposition follows from the fact that two important conflict-reducing agents - namely, intermediary relationships and cross-cutting cleavages - exist in a multipolar setting but are eliminated in a cluster bipolar one. Intermediary relationships involve the existence of a group of actors between the two enemy camps on a single dimension of conflict. The intermediaries, or actors in the middle, have a number of peacekeeping roles to perform. First, they play face saving roles. These include (1) good offices, or the offer of a neutral meeting ground (for ext ample, the French government made such an offer in 1968 to the U.S. and North Vietnam; both sides were able to accept Paris as a neutral meeting ground); (2) mediation, in which neutral parties propose peace solutions that would be unacceptable if they came from the enemy camp (for example, Kissinger's Middle East shuttle diplomacy); and (3) arbitration, in which neutral parties have decisive powers in resolving the dispute (and which is therefore rarely employed). In addition, the intermediaries, by simply playing their role as moderates who do not have extremely hostile relations with anyone, can set the tone of political argument in the entire system. The more numerous the intermediaries, the more moderate will be this overall tone. A similar moderating effect has been observed in class conflict within nations: in class politics in industrial societies, the emerging new middle class has played such a moderating role (Dahrendorf 1959, p. 51).

The peacekeeping roles of intermediaries are determined by their spatial location between enemy camps. Because the intermediaries are not extremely distant from either side, they have moderately good relations with both sides. This insures that the intermediaries will have relatively tranquil relations with virtually all members of the system, in contrast to the nations on the extremes who necessarily view each other across a distance twice as great. This tranquility provides a basis from which the intermediaries can provide good offices and act as mediators and arbitrators of disputes.

The above model assumes that intermediary relationships occur along a single dimension of conflict. When conflicts are more than one-dimensional, a second conflict-reducing agent may be introduced in multipolar settings, namely, cross-cutting cleavages (Rae \& Taylor 1970 , pp. 85-92). Whereas the impact of intermediary relations stems from the relatively low distance (i.e., dissimilarity) between the intermediaries and the extremists, the impact of cross-cutting cleavages depends not on distance but on the hostility-reducing impact of cross-cutting alliance bonds. In the words of an ancient saying, 'the enemy of my enemy is my friend'. Thus, if Egypt and Saudi Arabia, which fought each other in Yemen in the $1960 \mathrm{~s}$, shared a common hostility towards Israel, the common hostility would act as a bond holding them closer together than they would otherwise be. If Jordan, Israel, and Saudi Arabia face a common threat from Arab extremists, they are distracted from their hostility for each other and forced to concentrate on their common threat. If Saudi Arabia and the U.S., which differ over Israel, sense a common interest in blocking radical socialism in the Arab world, this will lead them to realize that differences over Israel need not constitute an insurmountable barrier to friendship. A multitude of such crosscutting loyalties, in which a nation's opponent on one issue becomes its ally on another, make a nation aware that it may have shared interests with all actors - including actors with which it would have been purely and dimetrically opposed in a one-dimensional conflict.

As some of the examples may suggest, however, cross-cutting cleavages are not an unmixed blessing. A party that feels itself threatened along one dimension of conflict has an incentive to exacerbate tensions along another, in a way that can split the opposing 
coalition. Such strategies increase hostility between members of the system and increase the risk of violence. This is a rule that applies to all levels of conflict. In the example above, for instance, the Soviet Union, trying to penetrate the Arab world in the face of Arab distaste for Soviet style communism, has found favor with the militant Arabs by arming them for war against Israel. Similarly, Saudi Arabia's monarchy can reduce the threat it faces from radical Arabs by taking the forefront in financing the struggle against Israel. A similar phenomenon occurs in American domestic politics. Since the New Deal, the Democrats have been the majority party. Furthermore, on economic issues the Democrats have enjoyed the support of the majority of the American public. Aspiring Republican politicians have therefore been tempted to exacerbate symbolic cross-cutting issues such as the Red-scares and law-and-order in order to win some of the Democratic voters over to the Republican camp. These tactics have sometimes brought success at the polls, but have embittered the political climate within the United States. Thus, cross-cutting cleavages can act to reduce hostility and distance, but they can also be exploited with the opposite effect.

Intermediary functions are the consequence of the relatively short distances from the intermediaries to the wings. Cross-cutting functions, rather than the consequence of distances, are a cause acting over time to reduce the distance that would otherwise exist between hostile pairs in a one-dimensional conflict, but sometimes inducing an increase in distance and hostility.

\section{The classic debate revisited}

In their debate on polarity, Deutsch and Singer and Waltz are divided by two differences. The first is a genuine disagreement about the effect of multiple sources of stimuli. Waltz argues that multiple stimuli are confusing and dangerous, and that therefore a simple, bipolar world is safer. Deutsch and Singer argue that these multiple stimuli, by diluting attention, lessen the likelihood of a vicious cycle of increased tension and reciprocal arms buildups. The ability to completely focus attention on one enemy pole would occur, in the language of this paper, if power were absolutely bipolar or if clustering were absolutely bipolar. In either case, the only important opponents would be located at one point, and attention could focus on that point. To the degree that the system becomes multipolar in both senses, attention can no longer be focused on just one enemy, and attention becomes diluted. With theoretical predictions leading in opposite directions, it becomes an empirical question whether multiple stimuli will either produce a more peaceful system or a more violent one.

The second disagreement is partly semantic. Waltz argues that superpower dominance makes a bipolar world stable, while Deutsch and Singer argue that cross-cutting cleavages and mediators make a multipolar world stable. Waltz's argument that power bipolarity is more stable than power multipolarity (proposition 2 above) is not fundamentally in conflict with Deutsch and Singer's contention that cluster multipolarity is more stable than cluster bipolarity (proposition 3 above). Both may simultaneously be correct.

\section{Empirical evidence, 1815-1965}

These two propositions can be tested, in an exploratory way, with existing data. The Correlates of War Project has produced data over a long enough time series to allow variation in systemic polarization and to observe the impact of such variation on warfare (Singer \& Small 1968 and 1972, Singer, Bremer \& Stuckey 1972). The series so far gathered do not always allow the ideal operationalization of concepts; as a result, there is the danger that hypotheses may be accepted or rejected prematurely, on the basis of inappropriate specification or operationalization. The data analysis which follows should therefore be regarded as preliminary, and not as a definitive test of the hypotheses from the theory.

To insure as much of an independent test of the theory as possible, no data were 
analyzed until after the theory had been constructed, circulated among colleagues, and put in final form. In this way, the hypotheses are derived from the historical examples and reasoning of the first part of this paper, and not from prior exploration of the data set.

\subsection{Measurement}

The test of hypotheses in the paper is based on analysis of the system of interactions among the major powers. ${ }^{4}$ As defined by Singer \& Small (1972), this major power system varied in number from four to eight members during the period from 1815 to 1965 . This is an appropriate group of states to analyze for two reasons. First, a focus on the major powers insures that one will examine only states that do interact significantly with each other; it is a focus on states 'which almost by definition - are highly interdependent one with the other', and hence are guaranteed to make up a true 'system' (Singer et al. 1972, p. 22). Second, the major powers were the nations with the capabilities and predilections to engage in the rivalries associated with the balance of power and the balance of terror. It is among such a group of states, competing with and observing each other, that one would expect hypotheses about polarity to be confirmed. In 1816 , at the dawn of the period to be studied, these major powers were Austria-Hungary, England, France, Prussia, and Russia. The group grew to include at various times Italy, Japan, the United States, and China. Some members dropped out, so that by 1965 the major powers were again five in number.

In the analysis below, measurements will be made on the major powers at five year intervals, from 1815 to 1965 . To avoid the distorting effects of the world wars, and to maintain consistency with earlier research, these intervals of measurement are thrice modified, with readings taken in 1913 rather than 1915, in 1938 rather than 1940, and in 1946 rather than 1945.

The main index of warfare is the magnitude of war, measured in nation-months of interstate war, as reported in Singer \& Small (1972) and Singer, Bremer \& Stuckey (1972, p. 29). Also measured was the frequency of interstate wars fought by major powers. These war indices all cover a five-year period following the moment at which system polarization is measured; for example, if polarization is measured in January 1820 , warfare is measured from January 1820 through December 1824.

Two measures of power concentration were employed in the present study. One, reported by Singer, Bremer \& Stuckey (ibid.), measures the inequality of the capabilities of the major powers. This index is based on the standard deviation of the capabilities of the major powers; this number approaches zero when the major powers are roughly equal in capabilities. The second index, derived from the SingerBremer-Stuckey data set, is a computation of the percentage of major power capabilities held by the two greatest powers. ${ }^{5}$ These two indices are highly correlated with each other $(r=.90$ for $1815-1965, r=.75$ for the nineteenth century, and $r=.93$ for the twentieth century), and tend to produce very similar results in hypothesis testing. By either measure, power concentration was lowest around the turn of the century and just before World War II (see Table II).

Measuring the clustering of the system is more difficult than measuring warfare or power concentration. Perhaps the ideal data would be scaling of hostility and friendship levels gleaned from content analysis of diplomatic documents. Such data are not directly available for the time span being examined. The best available data are the data on alliances. ${ }^{6}$ While alliance data measure one aspect of cooperation between pairs of states, they are not without their problems. One difficulty is that alliances may be an intervening variable between more basic displays of hostility/friendship and the outbreak of war. This difficulty makes it dangerous to attribute causal significance to the correlations examined below. A second problem is that the major power alliance data are not rich enough in information to be subjected to multidimensional scaling analysis. The cluster 
Table II. Two Measures of Power Polarization.

\begin{tabular}{|c|c|c|c|c|c|}
\hline Year & CONa & TWOCONB & Year & $\mathrm{CON}$ & TWOCON \\
\hline 1815 & $-\cdots-$ & -- & 1895 & .223 & .47 \\
\hline 1820 & .241 & .58 & 1900 & .202 & .44 \\
\hline 1825 & .233 & .58 & 1905 & .207 & .43 \\
\hline 1830 & .242 & .58 & 1910 & .212 & .45 \\
\hline 1835 & .243 & .57 & 1913 & .208 & .46 \\
\hline 1840 & .232 & .57 & 1920 & .371 & .61 \\
\hline 1845 & .257 & .57 & 1925 & .247 & .52 \\
\hline 1850 & .260 & .57 & 1930 & .241 & .48 \\
\hline 1855 & .276 & .58 & 1935 & .228 & .51 \\
\hline 1860 & .280 & .57 & 1938 & .217 & .48 \\
\hline 1865 & .255 & .56 & 1946 & .417 & .90 \\
\hline 1870 & .233 & .51 & 1950 & .293 & .65 \\
\hline 1875 & .225 & .50 & 1955 & .331 & .69 \\
\hline 1880 & .226 & .49 & 1960 & .303 & .66 \\
\hline 1885 & .208 & .48 & 1965 & $\ldots-\ldots$ & $\ldots$ \\
\hline 1890 & .203 & .48 & & & \\
\hline
\end{tabular}

a. CON is the concentration index of major power capabilities reported in Singer, Bremer and Stuckey, 'Capability Distribution, Uncertainty, and Major Power War,' p. 22.

b. TWOCON is the percentage of major power capabilities held by the two largest powers.

analysis that can be performed does not allow separate measurement of the degree of intermediation and the degree of cross-cutting in the system.

On the basis of the alliance data, a polarization index was constructed. To do this, a 'bloc' was defined as a set of nations each of which had a defense pact with each of the others; for example, in 1955, France, the United States, and the United Kingdom formed a bloc. The number of 'poles' in the system is equal to the number of blocs plus the number of non-bloc major powers. Cluster bipolarity would exist if there were only two poles. The maximum number of potential poles in any year is of course identical to

Table Ill. Alliance Polarization.

\begin{tabular}{lccc}
\hline Year & $\begin{array}{c}\text { Alliance } \\
\text { polarizationa }\end{array}$ & Year & $\begin{array}{c}\text { Alliance } \\
\text { polarization }\end{array}$ \\
\hline 1815 & .40 & 1895 & .56 \\
1820 & .20 & 1900 & .62 \\
& (UNIPOLAR) & 1905 & .50 \\
1825 & .80 & 1910 & .50 \\
1830 & .80 & 1913 & .50 \\
1835 & .60 & 1920 & .80 \\
1840 & .40 & 1925 & 1.00 \\
1845 & .60 & 1930 & 1.00 \\
1850 & .80 & 1935 & .86 \\
1855 & .80 & 1938 & .86 \\
1860 & .83 & 1946 & 1.00 \\
1865 & .83 & 1950 & .40 \\
1870 & 1.00 & 1955 & .40 \\
1875 & .83 & 1960 & .40 \\
1880 & .83 & 1965 & .60 \\
1885 & .67 & & \\
1890 & .67 & .60 & \\
\hline
\end{tabular}

a. A value of 1.0 represents maximum alliance multipolarity. Low values represent clustering of the system into blocs, thereby tending toward alliance bipolarity. 
the number of major powers. The formation of blocs, by reducing the number of poles, cuts down on the potential for cross-cutting cleavages and intermediary roles. The ratio of actual poles to potential poles was used as a measure of alliance polarization. The ratio would reach 1.0 under maximum cluster multipolarity, when there are no blocs; it would approach 0.0 under cluster bipolarity (or, as in the unique case of the Holy Alliance of 1820 , unipolarity). This index is presented in Table III.

The main periods of bipolarity, when the index is at its lowest values, were just before World War I and during the Cold War.

\subsection{Correlations and hypothesis testing}

With the indices constructed, it was possible to test several of the theoretical claims from the first section of the paper. One of the important findings of the data analysis is that power polarity and cluster polarization are in fact separate dimensions. Indeed, using the measures developed for this study, the two concepts are almost totally uncorrelated with each other. Over the period 1815-1965, the alliance polarization index correlates 0.01 with the measure of bipolar power concentration (TWOCON) and 0.12 with the SingerBremer-Stuckey measure of power concentration (CON). In the nineteenth century, the alliance polarization measure correlates -0.28 with TWOCON and 0.13 with CON. In the twentieth century, these correlations are 0.10 and 0.16 , respectively. None of these correlations are statistically significant at the .05 level. $^{7}$

This complete lack of association between measures of power concentration and alliance polarization has implications both for the polarization literature already discussed and for the theoretical work of Snyder \& Diesing (op.cit. pp. 419-470). Of course, as noted at the outset, if the two aspects of 'bipolarity' are not even statistically associated with each other, then the early literature that classified all international systems as either 'bipolar' or 'multipolar' needs to be refined. Whereas the early literature on polarity did tend to collapse power bipolarity and alliance bipolarity into a single concept, Snyder and Diesing are careful to distinguish 'system structure' (the number of major powers and the distribution of capabilities) from the alliance patterns in the system. However, Snyder and Diesing do see a causal connection between the two concepts; they argue that a bipolar power concentration tends to produce alignments in which the lesser powers cluster around the two largest powers. ${ }^{8}$ The findings of this paper put a greater emphasis on the distinction between power concentration and alliance configuration than do Snyder and Diesing, who, after all, argue that the power polarity variable has a causal impact on the alliance patterns variable, while the two concepts as measured in this paper are statistically independent. Snyder and Diesing have based their argument on references to the post-World War II environment. Rapkin, Thompson, and Christopherson do find a positive correlation between bipolarity and bipolarization in the Cold War period, but one should hestitate to generalize those results to earlier eras, given the findings of the present paper.

One possible reconciliation of the findings with Snyder and Diesing would be to argue that a bipolar power concentration does produce a bipolar alliance configuration, but only when the power concentration surpasses a very high threshold, as it did in the late 1940 s and early 1950 s. A second possibility is that ideological fervor, having been a major cause of alliance formation after World War II, was covarying with power concentration and hence causing a portion of the correlation reported by Rapkin, Thompson, and Christopherson. ${ }^{9}$ Certainly, the era of John Foster Dulles was a time when the U.S. formed many alliances, such as CENTO, which were appropriate to the operational code and ideology of foreign policy officials, but which may have done little to enhance the interests of the United States. Third, it is possible (indeed, likely) that future studies, based on improved measures of bipolar power concentration and bipolar alliance configuration, will yield revised findings of the relation- 
Table IV. Power Polarization and the Magnitude of Major Power Inter-State War, 1815-1965.

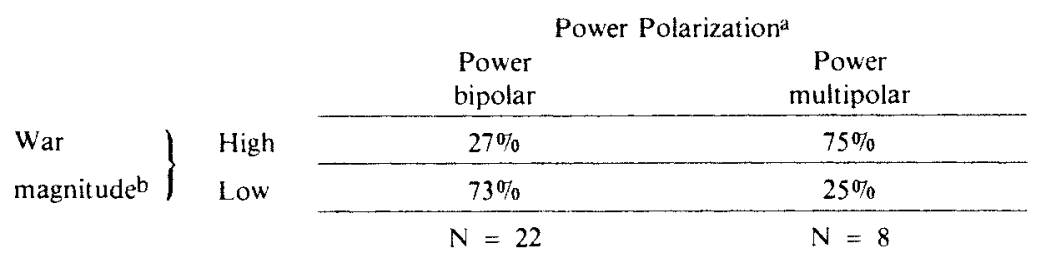

Tau B $=-.43$

(Significance level $=.02$ for a non-directional hypothesis).

a. A system is treated as power bipolar if the two largest powers have at least fifty percent of major power capabilities. Otherwise it is treated as power multipolar.

b. High war magnitude is treated as more than ten nation-months of major power inter-state war. Less than ten nationmonths is considered low war magnitude.

ship between the two concepts. ${ }^{10}$ At the present time, when virtually no one reports validity coefficients for new measures of polarization, it is difficult to ascertain in what ways the alliance indicator used in the present paper would correlate with some factors from earlier efforts to measure the same thing. ${ }^{11}$ So the debate about the above findings is by no means settled, and should continue.

For the sake of hypothesis testing in the remainder of this paper, the important fact is that the independent variables (power concentration and alliance configuration) in the following tests are indeed statistically independent of each other.

The first hypothesis, relating the amount of warfare in the system to the amount of hostility in the system, cannot be tested with the data presently available. While such a test would in all likelihood be a demonstration of the obvious, it would be useful as a way of controlling for effects that may disturb the testing of hypothesis three, as will become clear below.

The second hypothesis suggests that power bipolarity should minimize the size of any wars that might break out. The data are somewhat supportive of this hypothesis. If we classify relatively bipolar systems as ones in which the two largest powers have over fifty percent of great power capabilities, we find that the major power system was power multipolar thirty-four percent of the time, and power bipolar in the other years. The power multipolar years were, if anything, slightly less war prone. Only twenty-seven percent of the major power inter-state wars broke out in those years, and this is slightly, though insignificantly, below the thirty-four percent that would have occurred by chance. The second hypothesis contends, however, that any wars that did break out under power multipolarity would be massive conflagrations. Table IV confirms this hypothesis. Three-quarters of the wars under power multipolarity were of high magnitude. These included World Wars I and II. In contrast, three-quarters of the wars under power bipolarity were of low magnitude. While the size of this correlation does shrink somewhat if different cutoffs are chosen for the two dichotomies, the correlation does remain supportive of the arguments in the theoretical section of this paper. This is important because it is the opposite of what some scholars would have expected. Some scholars have argued that in a multipolar world, adjustments to the system occur through frequent but low level warfare, whereas in a bipolar world, wars are less frequent but bigger. One of the most explicit statements of this position is made by Michael Haas (1970, p. 121): 'bipolarity brings fewer but longer wars.' Rosecrance (1969, p. 329) offers a more qualified assertion of the same position: 
Table V. Cross-Lagged Correlations between War (Magnitude of Major Power Inter-state war Underway) and Cluster Multipolaritya.

\begin{tabular}{|c|c|c|c|c|c|c|}
\hline \multirow[b]{2}{*}{$\begin{array}{l}\text { Correla- } \\
\text { tions } \\
\text { of }\end{array}$} & \multicolumn{2}{|c|}{$1815-1965$} & \multicolumn{2}{|c|}{$\begin{array}{l}\text { Twentieth } \\
\text { century }\end{array}$} & \multicolumn{2}{|c|}{$\begin{array}{l}\text { Nineteenth } \\
\text { century }\end{array}$} \\
\hline & $\begin{array}{l}\text { War lagged } \\
\text { before } \\
\text { alliance } \\
\text { multi- } \\
\text { polarity }\end{array}$ & $\begin{array}{l}\text { War } \\
\text { following } \\
\text { alliance } \\
\text { multi- } \\
\text { polarity }\end{array}$ & $\begin{array}{l}\text { War lagged } \\
\text { before } \\
\text { alliance } \\
\text { multi- } \\
\text { polarity } \\
\end{array}$ & $\begin{array}{l}\text { War } \\
\text { following } \\
\text { alliance } \\
\text { multi- } \\
\text { polarity } \\
\end{array}$ & $\begin{array}{l}\text { War lagged } \\
\text { before } \\
\text { alliance } \\
\text { multi- } \\
\text { polarity }\end{array}$ & $\begin{array}{l}\text { War } \\
\text { following } \\
\text { alliance } \\
\text { multi- } \\
\text { polarity } \\
\end{array}$ \\
\hline $\begin{array}{l}\text { Static } \\
\text { measures }\end{array}$ & Sig. $=.49$ & $\begin{array}{c}-.13 \\
\text { Sig. }=.52 \\
\end{array}$ & $\begin{array}{l}.18 \\
\text { Sig. } \\
\end{array}$ & $\begin{array}{c}-.14 \\
\text { Sig. }=.64\end{array}$ & $\begin{array}{c}.70 \\
\text { Sig. }=.006\end{array}$ & $\begin{array}{l}.43 \\
\text { Sig. } \\
\end{array}$ \\
\hline $\begin{array}{l}\text { First } \\
\text { differences }\end{array}$ & Sig. $=.03$ & $\begin{array}{l}-.46 \\
\text { Sig. }=.01\end{array}$ & Sig. $\stackrel{.49}{=} .07$ & $\begin{array}{l}-.56 \\
\text { Sig. }=.03\end{array}$ & $\begin{array}{c}.47 \\
\text { Sig. }=.11\end{array}$ & Sig. $=.69$ \\
\hline
\end{tabular}

a. Pearson product-moment correlation coefficients with significance levels for non-directional hypothesis. Italicized figures show statistical significance at better than the .05 level for a directional hypothesis.

'It seems highly probable that a multipolar world order will increase the number of conflicts, though it may possibly reduce their significance.' Such contentions seem to be the opposite of the findings of the present paper that wars are more frequent but of lesser magnitude under power bipolarity. While Haas offers some statistical support for his position, his findings may be based upon impressionistic coding schemes that categorized, for example, all historical systems, in a dichotomous fashion, as 'bipolar' or 'multipolar', without clarifying whether the judgments were based on power concentration or alliance configuration. In short, the reproducible evidence seems to support proposition two.

The third hypothesis, relating the amount of war to the cluster polarization of the system, is more difficult to test with existing data. Because war, hostility, and even anticipated war have a reciprocal causal impact on alliance patterns, it is difficult to measure the causal impact of alliance bipolarity on war. Given these reciprocal causal linkages, it would be best in testing the model to have measures of variables that cause alliance patterns but not war, and other variables that cause war but not alliance patterns. Without such measures, the best evidence available is the cross-lagged correlations between war and alliance polarization (see
Table V). The cross-lagged correlations cannot be used for causal conclusions. The autocorrelations for alliance polarization are 0.44 in the nineteenth century, 0.59 in the twentieth century, and 0.52 for the entire period 1815 to 1965 ; for war magnitude, the autocorrelations are 0.72 in the nineteenth century, -0.32 in the twentieth century, and -0.15 for the entire period. With such nonzero autocorrelations, the cross-lagged correlations do not have clear causal interpretations, but can be used to suggest possibilities. To reduce the contaminating effect of the autocorrelations, the first differences were computed for both variables.

In Table $\mathrm{V}$, war is always positively correlated with subsequent alliance multipolarity: in both centuries, war seems to lead to a dispersion of alliance blocs. In the twentieth century, this cluster multipolarity is followed by peace (see the fourth column of Table V), as the third hypothesis contends. In the nineteenth century, however, the opposite of the hypothesis seems to hold true, and cluster multipolarity is followed by war (see the sixth column of Table V). Furthermore, in the nineteenth century, an increase in alliance multipolarity (from $t_{1}$ to $t_{6}$ ) is positively correlated $(r=.31)$ with the subsequent magnitude of war (the sum of nation-months from $t_{6}$ to $t_{11}$, indicating that prior to war alliance clusters were disintegrating. In the 
Table VI. Untested Explanation for Difference between the Two Centuries

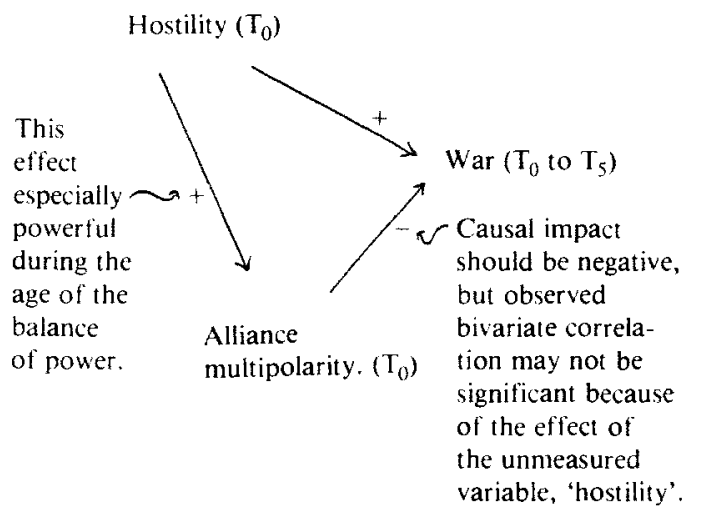

twentieth century, on the other hand, an increase in alliance multipolarity (from $t_{1}$ to $\left.t_{6}\right)$ is negatively correlated $(r=-.48)$ with the subsequent magnitude of war (the sum of the nation-months from $t_{6}$ to $t_{11}$ ), indicating that prior to wars the alliance patterns were becoming more bipolarized. These differences between centuries are similar to the ones found by Singer \& Small (1968) using several alliance and (cluster) bipolarity measures, all different from the ones used here.

Why are correlations from Table $\mathrm{V}$ significant, and even in the wrong direction, in the nineteenth century? One possibility that is consistent with the theoretical structure of this paper involves the total hostility in the system. This hostility could rise to very high levels in years of intense conflict between groups of states. Especially in the nineteenth century, during the balance of power era, hostility and the subsequent threat of war might induce nations to hedge their bets by dropping out of blocs to maintain maximum flexibility by cultivating many potential allies. Meanwhile (see Table VI), the hostility could also lead to war. Even if the alliance multipolarity were itself having a pacifying effect on the system, the bivariate correlation between multipolarity and war could yield an insignificant result. If one could control for hostility, the correlation might change enough to confirm the third hypothesis.
The statistically significant correlation supporting hypothesis three is the correlation of first differences $(r=-.56)$ for the twentieth century. This correlation means that a system that has become more alliance multipolar than in the previous time period will experience significantly less war than in that earlier time period. These first differences measure velocities - the rate at which the system is becoming more warlike, and the rate at which it is becoming more cluster bipolar.

Technically, the correlation for the first difference is also significant for the entire 1815 to 1965 period (as can be seen in the second column of Table V). This finding considered alone would confirm proposition three for both centuries. But the separate analyses of each century indicate such disparate results that such a conclusion would appear to be an overgeneralization. The nineteenth and twentieth centuries do seem substantially different.

While this finding for the twentieth century is consistent with the theoretical argument and with hypothesis three, it appears to be the opposite of the finding of Bueno de Mesquita in his analysis of the same century. ${ }^{12}$ He computes the number of 'poles' among all system members (not just major powers), and then computes the number of interaction opportunities among poles. (The number of such opportunities is found by multiplying the number of poles times that number minus one, and then dividing by two. When the system is multipolar, there will be many interaction opportunities.) He finds that the amount of war in the subsequent five years is positively correlated with the number of interaction opportunities (a correlation of .32) and with a shift towards more interaction opportunities than had been available five years before (a correlation of .52).

How can Bueno de Mesquita's findings be reconciled with the present findings? First, he is focusing on the polarization of the entire 'system', while this paper focuses only on the major power system. Second, and related to the first point, his count of interaction opportunities swells as system size 
Table VII. Correlations between Selected Indicators of Cluster Polarization. ${ }^{a}$

\begin{tabular}{|c|c|c|c|c|c|c|c|c|c|c|}
\hline Variable & $\begin{array}{c}\text { States } \\
\text { included }\end{array}$ & Concept & $\mathrm{V} 1$ & $\mathrm{~V} 2$ & $\mathrm{~V} 3$ & V4 & V5 & $V_{7}$ & V8 & V9 \\
\hline $\begin{array}{l}\text { Wayman Bi- } \\
\text { polarization* (V1) }\end{array}$ & majors & $\begin{array}{c}\text { Clusters as a proportion } \\
\text { of potential clusters }\end{array}$ & 1.0 & & & & & & & \\
\hline 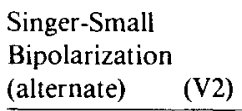 & majors & $\begin{array}{l}\text { Alignments as proportion } \\
\text { of potential alignments } \\
\text { (omits debatable targets) }\end{array}$ & .66 & 1.0 & & & & & & \\
\hline $\begin{array}{l}\text { Singer-Small } \\
\text { Bipolarization } \\
\text { (initial) (V3) }\end{array}$ & majors & $\begin{array}{l}\text { Alignments as proportion } \\
\text { of potential alignments } \\
\text { (includes all targets) }\end{array}$ & .62 & .75 & 1.0 & & & & & \\
\hline $\begin{array}{l}\text { Singer-Small } \\
\text { Alliance } \\
\text { Aggregation (V4) }\end{array}$ & all & $\begin{array}{l}\text { Alignments as proportion } \\
\text { of possible alignments }\end{array}$ & -.06 & .04 & .22 & 1.0 & & & & \\
\hline $\begin{array}{l}\text { Li \& Thompson } \\
\text { Cluster* (V5) }\end{array}$ & majors & $\begin{array}{c}\text { Number of discrete } \\
\text { clusters }\end{array}$ & .42 & .50 & .64 & .71 & 1.0 & & & \\
\hline $\begin{array}{l}\text { Li \& Thompson } \\
\text { Alliance (V6) }\end{array}$ & majors & $\begin{array}{l}\text { Dyads with defense pacts } \\
\text { as proportion of possible }\end{array}$ & .35 & .48 & .48 & .70 & 1.0 & & & \\
\hline $\begin{array}{l}\text { Bueno de Mesquita } \\
\text { Poles* }\end{array}$ & all & Number of poles & .30 & .15 & .24 & -.61 & $-.06-.30$ & 1.0 & & \\
\hline $\begin{array}{l}\text { Bueno de Mesquita } \\
\text { Tightness (V8) }\end{array}$ & all & Tightness of Poles & -.01 & -.14 & .21 & .58 & .19 & -.08 & 1.0 & \\
\hline $\begin{array}{l}\text { Bueno de Mesquita } \\
\text { Discreteness (V9) }\end{array}$ & all & Discreteness of Poles & .13 & -.09 & .12 & -.24 & $-.04-.15$ & .47 & .34 & 1.0 \\
\hline
\end{tabular}

grows. For example, the present measure indicates that the 1950 s were the decade of greatest alliance bipolarity since the Napoleonic Wars. His measure, which is affected by the growth in the number of independent nations, indicates that the 1950 s were one of the four decades with the greatest amount of alliance multipolarity. Such disagreements about a well-known decade illustrate how two measures of alliance polarization might be weakly correlated, uncorrelated, or even negatively correlated with each other. Such correlations do not invalidate either measure, nor should the measures be attacked solely by appeals to face validity. ${ }^{13} \mathrm{I}$ have chosen major powers as the focus of measurement, however, because I remain unconvinced that the clusters of minor powers would have much causal effect on the war proneness of the major power system. For example, in 1960,
Bueno de Mesquita reports a cluster made up of Finland and Mongolia. The mere existence of this cluster, in a world with ten other clusters, increases the total interaction opportunities by ten (from forty-five to fifty-five), according to Bueno de Mesquita's formula. (In contrast, the average number of interaction opportunities in the nineteenth century is about one.) According to the Bueno de Mesquita formula, the impact of the Finland-Mongolia cluster is the same as the impact of NATO. My own view of the international system, from 1815 to 1965 , puts much more emphasis on power stratification; on the dominance of the core powers over the rest of the nation-members of the system; and on the tendency for major-major and even major-minor interactions to dominate over minor-minor interactions. ${ }^{14}$ Therefore, I am very skeptical of any alleged causal implica- 
tions that are based on assumptions that major and minor powers can be treated interchangeably and I have more confidence in the possible causal importance of bivariate correlations based on analyses of major-major interactions, for the period from 1815 to 1965. Until such conflicting measurement assumptions are reconciled, and until we can control for all plausible rival hypotheses, we will continue to encounter more or less plausible, but conflicting, findings in the literature.

The disagreement between this paper and the Bueno de Mesquita indicators is not unique; rather, each scholar who has attempted to measure 'alliance polarization' or 'cluster polarity' has developed his own idiosyncratic algorithm, and. no one has documented the correlations betwen his indicator and others that have gone before. The resulting Tower of Babel is illustrated by Table VII, in which eight published indicators of cluster polarity (as stored in the Correlates of War Project data archives) are compared to each other and to the cluster polarization indicator used in the current paper. (In Table VII, the sign of three indicators has been reversed in order to insure that as may correlations as possible are positive; this means that any negative correlations will point to measures of cluster polarization that have produced reversed results.) A glance at the table shows that the eight indicators by Singer and Small, $\mathrm{Li}$ and Thompson, and Bueno de Mesquita clearly are measuring (hopefully because of the different intentions of the authors) fundamentally different things. The patterns are most disconcerting for the indicators based on all nationstates. For example, the Singer and Small alliance aggregation measure is correlated, at the .01 level of statistical significance, negatively with one Bueno de Mesquita measure (number of poles) and positively with another (tightness of poles). The measures of polarization in the major power system are more convergent with each other. The $\mathrm{Li}$ and Thompson and Singer and Small measures are all significantly correlated, in the positive direction, to each other. The measure used in the current paper is significantly associated, in the positive direction, with all of these prior measures of polarization of the major power system except one of the $\mathrm{Li}$ and Thompson measures, which falls barely short of statistical significance. As a general rule, the very weak associations are those between the major power system indicators and the indicators for all nation-states; the main exception to that rule is the strong relationship of the $\mathrm{Li}$ and Thompson measures to the Singer-Small alliance aggregation measure. While it is beyond the scope of the present paper, in the future it would be appropriate for literature reviews to consider these correlations before reaching conclusions about the meaning of the disparate findings that have been reported. It appears that cluster multipolarity is much more of a multidimensional concept than power bipolarity, and this point needs greater attention in texts and literature reviews. Meantime, for purposes of the present paper, it can be said that the indicator used, while unrelated to measures of cluster polarization for all nationstates, is significantly correlated with the bulk of the measures of major-power system cluster polarization, and to that extent is producing reliable results. Discrepancies with studies, such as Bueno de Mesquita's, which focus on the war-proneness of the system based on polarization patterns among all nation-states, are not surprising.

To summarize my findings, with regard to the two hypotheses tested in this paper, significant correlations exist which support the power polarity hypothesis in the whole period from 1815 to 1965 , and the spatial polarization hypothesis in the twentieth century. None of the correlations discovered in this paper, however, is large enough to account for over half the variance in the amount of war. Thus even the highest correlations in this study are not enough to support a monocausal explanation of warfare, and other variables besides system polarization are clearly relevant. Indeed, until these other potential causes are specified, 
measured, and included as control variables, causal inferences about polarization and warfare will remain only suggestive. As for the theory of polarization that has been presented, it cannot be proven by the confirmation of hypotheses derived from it. Other theoretical formulations might generate the same hypotheses. But the failure to disconfirm does lend some greater plausibility to the theory, and does raise serious questions about the contrary assertions of Haas, Bueno de Mesquita, and other authors discussed above.

\section{Conclusions}

Theoretically, this paper has contended that the Waltz thesis and the Deutsch and Singer thesis, classically juxtaposed in the literature, may both be valid. Waltz argues that bipolarity is more stable than multipolarity. It has been theorized in this paper that he is correct insofar as he refers to power bipolarity, which minimizes the magnitude of war, should a war break out. Deutsch and Singer argue that multipolarity is more stable. It has been theorized in this paper that they are correct insofar as they refer to cluster multipolarity, which is less likely to lead to war than is cluster bipolarity.

The correlational evidence analyzed above is mildly supportive of both these hypotheses, for the twentieth century. The power polarity hypothesis seems confirmed for the whole period from 1815 to 1965 . The cluster, or alignment, polarity hypothesis seems confirmed for the twentieth century. Significant correlations support it for the whole 18151965 period. But after separate bivariate analysis of each century, it seems disconfirmed for the nineteenth century, perhaps because of the effects of hostility on the balance of power alliance structures of that era.

If the findings for the twentieth century should prove valid, and the theory should be upheld, it would follow that a combination of power bipolarity and alignment multipolarity is the formula for stability in the modern era. The implications of such a per- spective for foreign policy making would include the encouragement of political diversity and multicentrism of alliance patterns, along with a discouragement of massive transfers and proliferations of weapons technologies that might destabilize the power bipolarity of the international system of our nuclear age. Whatever the empirical results may show, it is the heartening conclusion of this essay that the relevant arguments of Waltz and of Deutsch and Singer were valid and consistent with each other. Students of international politics who might have concluded that the arguments were contradictory could only have been discouraged at the level of theoretical integration and agreement in this area of the literature. If the theoretical structure of the present paper is sound, this potential area of disagreement has been replaced by a consistent theoretical structure based on a clearer understanding of the wisdom of both of these earlier theories.

\section{NOTES}

1. The author would like to thank Don Anderson, Mike Champion, Pat Dobel, Leo Hazlewood, Ceorge Liska, Clitif Morgan, Miko Ninčic, Al Sabrosky, David Singer, and the anonymous reviewers from $J P R$ for their comments on this paper. Special thanks are due to J. David Singer for his recommendations concerning the paper, and also for the highly collegial and cooperative atmosphere that he maintains at the Correlates of War Project. Finally, thanks are due to Mike Champion, Cliff Morgan, and Judy Nowack for helping the author in gaining efficient access to the data that are analyzed in this paper.

2. The splitting of 'polarization' into two different dimensions, as is done here, is fundamentally different from the approach of Richard Rosecrance in his discussion of 'Bi-multipolarity'. He treats this concept as an 'intermediate' level of a unidimensional continuum from bipolarity to multipolarity. As such, his concept mixes a discussion of power concentration with a discussion of coalition clustering without distinguishing the two. It thereby carries forward the ambiguities inherent in the Deutsch, Singer, and Waltz debate. See Rosecrance (1966).

3. Coalition configuration and power concentration have been presented as dichotomous variables to 
simplify discussion in the historical examples and definitions above; they will be treated as continuous variables in the measurement section of the paper.

4. In this it differs from alliance analyses that include all members of the international system. These analyses include Bueno de Mesquita (1975), and Wallace (1973).

5. The data base, from the Correlates of War Project, is an updated version of that reported in Singer, Bremer \& Stuckey (1972).

6. Singer \& Small (1968). Trade has also been proposed as an indicator of 'bipolarization', or cluster polarity. See Goldman (1974) and Wall (1972). Goldman and Wall demonstrate the relevance of trade, aid, and related data to measures of post-World War 11 polarization patterns. Trade data, however, do not exist, even for all the major powers, back to 1816 , so statistical analyses of trade and international conflict have been limited to the twentieth century. Extensive C.O.W. analyses of trade volume and trade dependency have failed to detect any relationship between trade and militarized disputes or war, 1950-1976. These studies were path breaking in that they examined not only trade volume, but also the marginal utilities for imports and exports of each side (using price elasticities of supply and demand). See Huelshof \& Soltvedt (1981). Their study was discouraging because of the persistent absence of statistically significant relationships between trade and disputes or war. Given this experience, given the already monumental task of treating power concentration and alliance polarization, and given the dearth of trade data over the 18151965 period, trade was not included in the present study.

7. Within a specific historic period, cluster polarity and power polarity may be more highly correlated. Such a correlation is suggested by the findings of Rapkin, Thompson \& Christopherson (1979). Their sludy of the 1948-1973 era, published as the bulk of the present research was being completed, is based on COPDAB event data. While Rapkin, Thompson, and Christopherson arrive at their findings with radically different operationalizations, there are clear parallels between their concept of 'polarity' and the concept of 'power polarity' in the present study, as well as between their concept of 'polarization' and the concept of 'cluster polarity' in the present study.

8. Snyder \& Diesing (1977), pp. 420-421. This type of alliance configuration in similar to what Rapkin, Thompson \& Christopherson (1979) have called bipolarization.

9. See Bueno de Mesquita \& Singer (1973), pp. 237-273, and especially p. 264 , for a discussion of the role of ideology and other factors in alliance formation, and the need for more empirical research on the subject. For a thoughtful review of the state of the art, see Ward (1982).

10. Indeed, as already indicated by Bueno de Mesquita's work on tightness and discreteness, alliance polarization may very well itself be a multidimensional concept, as may power concentration (which involves both the number of major powers and the distribution of power among them).

11. On the more positive side, the correlation between two measures of power concentration - CON and TWOCON - has been reported above, at page 68 , and the correlations between a sample of cluster polarization measures are reported below, at page 74.

12. Bueno de Mesquita (1975, p. 206). Bueno de Mesquita focuses on wars involving at least one major power, and the present study has also focused on the set of major-major and major-minor wars. The measure of alliance multipolarity in the present paper does not exactly correspond to his measures of interaction opportunities, number of clusters, tightness, and discreteness, of course.

13. See Lee Cronbach (1970, pp. 121-124) for a discussion of construct validation and an introduction to the literature on validation.

14. While this view originated with conservative realists, it is shared by many radicals as well. See Daniel Chirot (1977) for a summary of this perspective on the world system.

Ostrom \& Aldrich (1978) have moditied the Bueno de Mesquita data in a manner somewhat consistent with this view. They calculated the number of independent clusters that included at least one major power. They then added the number of non-aligned major powers to the initial total. The resulting grand total is the sum of all the major-major and major-minor clusters and the number of non-aligned major powers. This measure will probably still be sensitive, as the underlying Bueno de Mesquita index is, to the sheer growth in the number of minor powers during the twentieth century.

Ostrom and Aldrich take the surprising but useful approach of reducing most of the literature on polarity to a set of hypotheses about the number of independent actors. While their approach produces interesting and fruitful results, it is limited by this choice they have made about how to interpret the theoretical literature. Leaving aside attempts to incorporate crosscutting cleavages, intermediary roles, divided attention, discreteness and tightness, they find support for George Liska's conclusion that the mere number of independent actors may not matter very much. 


\section{REFERENCES}

Alcock, N. \& A. Newcombe, 1970. 'The Perception on National Power', Journal of Conflict Resolution, vol. 14, no. 3, pp. 335-343.

Bueno de Mesquita, Bruce, 1975. 'Measuring systemic Polarity', Journat of Conflict Resolution, vol. 19, no. 2, pp. 187-216.

Bueno de Mesquita, Bruce \& J. David Singer, 1973. 'Alliances, Capabilities, and War: A Review and Synthesis', in Cornelius Cotter, ed., Political Science Annual: An International Review, vol. 4. Indianapolis, Indiana: Bobbs-Merrill.

Chirot, Daniel, 1977. Social Change in the Twentieth Century. N.Y.: Harcourt, Brace and Jovanovich.

Cronbach, Lee, 1970. Essentials of Psychological Testing. N.Y.: Harper and Row.

Dahl, Robert, 1970. Modern Political Analysis, 2d ed., revised. Englewood Cliffs, New Jersey: Prentice Hall.

Dahrendorf, Ralf, 1959. Class and Class Conflict in Industrial Society. Palo Alto, Calif.: Stanford University Press.

Deutsch, Karl, et al., 1957. Political Community and the North Allantic Area. Princeton: Princeton University Press.

Deutsch, Karl \& J. David Singer, 1964. 'Multipolar Power Systems and International Stability', World Politics, vol. 16, no. 4 , pp. $390-406$.

Goldman, Kjell, 1974. Tension and Detente in Bipolar Europe. Stockholm: Esselte Studium.

Huelshof, Michael \& Lars Soltvedt, 1981. 'Economic Interdependence and the Escalation of Serious Disputes, Correlates of War Project mimeo.

Kagan, Donald, 1969. The Outbreak of the Peloponnesian War. Ithaca, N.Y. Cornell University Press.

Kaplan, Morton, 1957. System and Process in the International Politics. N.Y.: Wiley.

Klingberg, Frank, 1941. 'Studies in the Measurement of the Relations among Sovereign States', Psychomeirica, vol. 6, no. 6, pp. 335-352.

Knorr, Klaus, 1955. The War Potential of Nations. Princeton: Princeton University Press.

Ostrom, Charles W. \& John Aldrich, 1979. 'The Relationship between Size and Stability in the Major Power International System', American Journal of Political Science, vol. 84, no. 3, pp. 743-771.

Rae, Douglas \& Michael Taylor, 1970. The Analysis of
Political Cleavages. New Haven, Conn.: Yale University Press.

Rapkin, David, William Thompson, \& Jon Christopherson, 1979. 'Bipolarity and Bipolarization in the Cold War Era', Journal of Conflict Resolution, vol. 23, no. 2, pp. 261-295.

Riker, William, 1962. The Theory of Political Coalitions. New Haven, Conn.: Yale University Press.

Riker, William, 1969. 'Some Ambiguities in the Notion of Power', in R. Bell, ed. Political Power. N.Y.: Free Press.

Rosecrance, Richard, 1966. 'Bipolarity, Multipolarity, and the Future', Journal of Conflict Resolution, vol. 10, no. 3, pp. 314-327.

Sabrosky, Alan, 1975. 'From Bosnia to Sarajevo', Journal of Conflict Resolution, vol. 19, no. 1, pp. 3-24.

Singer, J. David, Stuart Bremer \& John Stuckey, 1972. 'Capability Distribution, Uncertainty and Major Power War, 1820-1965', in Bruce Russett, ed., Peace, War, and Numbers. Beverly Hills, Calif.: Sage Publications.

Singer J. David \& Melvin Small, 1968. 'Alliance Aggregation and the Onset of War', in J. David Singer, ed. Quantitative International Politics. N.Y.: Free Press.

Singer, J. David \& Melvin Small, 1972. The Wages of War. N.Y.: Wiley.

Snyder, Glenn \& Paul Diesing, 1977. Conflict among Nations. Princeton: Princeton University Press.

Wall, G. Roger, 1972. Bipolarization and the International System: 1946-1970. Stockholm: The Swedish Institute of International Affairs.

Wallace, Michael, 1973. 'Alliance Polarization, CrossCutting, and International War, 1815-1964', Journal of Conflict Resolution, vol. 17, no, 4, pp. 575-604.

Waltz, Kenneth, 1964. 'The Stability of a Bipolar World', Daedalus, vol. 93, no. 3, pp. 882-884.

Waltz, Kenneth, 1967. 'International Structure, National Force, and the Balance of World Power', Journal of International Affairs, vol. 53, no. 2, pp. 230-231.

Ward, Michael, 1982. Research Gaps in Alliance Dynamics. Denver, Colo.: University of Denver Monograph Series in World Affairs. 